\title{
Cooperative Program for Resources Engineering Between Kyushu University and Hokkaido University
}

\author{
Takashi Sasaoka $^{1 *}$, Hideki Shimada ${ }^{1}$, Koichiro Watanabe $^{1}$, Takeshi Tsuji ${ }^{1}$, Ryo Imai $^{1}$, Hajime Miki $^{1}$, Yasuhiro Fujimitsu ${ }^{1}$, \\ Yuichi Sugai ${ }^{1}$, Kotaro Yonezu ${ }^{1}$, Naoki Hiroyoshi ${ }^{2}$ \\ ${ }^{1}$ Department of Earth Resources Engineering, Kyushu University, Fukuoka, Japan \\ ${ }^{2}$ Division of Sustainable Resources Engineering, Hokkaido University, Japan
}

\begin{abstract}
Joint Program for Sustainable Resources Engineering was adopted as a Special Expenditure Project by the Ministry of Education, Culture, Sports, Science and Technology in Japan. In this project, in order to cultivate human resources who can contribute to Japan's resource strategies, Education and Research Departments of Resources Engineering at Kyushu University and Hokkaido University aim to jointly establish a new collaborative education program in 2017. This is the first of its kind in the resources engineering area among universities in Japan. One of the pillar of this program is "International Field Practice". For working actively and globally in the field of sustainable resources engineering, one need to (1) acquire internationally accepted knowledge and techniques in the fields, (2) be capable of utilizing the knowledge and techniques practically, and (3) understand cultures in foreign countries as well as global trends in the field. In this exercise, students work on an internship or conduct a field research in a foreign country in the field of sustainable resources engineering. Through this exercise, students learn how to develop their leadership and adaptability in the world, and to communicate scientifically and technically in English presentation, discussion, and writing. This paper describes the overview of this program and the International Filed Exercise 2017 conducted in Czech Republic.
\end{abstract}

Keywords: joint degree program, resource engineering, global leader, international field exercise

\section{Introduction}

The global situation surrounding mineral resources has been drastically changing since the beginning of the 21 st century. As a result, resource nationalism, in which some governments use mineral resources in their own countries as trump cards of political and economic issues, has been gaining power. In order to secure stable resources, it is necessary for Japan to develop individuals with advanced expertise and international mindedness who will play a key role in resource strategies for the future.

For this reason, universities and graduate schools involved in fostering specialists need to comply with such social demands. There are, however, only a few universities and graduate schools providing comprehensive education programs for resources engineering throughout the country. In the current situation, therefore, it is difficult to fulfill such demands. Specifically, there are three problems: (1) Due to the shortage of faculty members engaged in training students in resources engineering, there are some academic fields that cannot be covered by a single university. (2) Compared to engineering education, management education is insufficient. In addition, if we see the overall picture of research and education in resources engineering in Japan, (3) the way each university uses its research and education resources (education programs and facilities) is inefficient.
As one of the methods to solve these issues, it is considered that several universities involved in education of resources engineering should work together to develop human resources. Education and research departments in resources engineering at Kyushu University and Hokkaido University (the Kyushu University Faculty of Engineering Department of Earth Resources Engineering and Hokkaido University Faculty of Engineering Division of Sustainable Resources Engineering) have been cooperating and collaborating concerning specific projects and events. In order to make their collaboration organic and full-fledged, this project establishes a collaborative graduate school education program (master's course).

This paper describes the overview of this program and the International Filed Exercise 2017 conducted in Czech Republic.

\section{The Joint Program for Sustainable Resources Engineering}

The collaborative graduate school education program is not only simply a combination of two existing curriculums in both universities, but also a new education program, which appropriates for fostering students in resources engineering for the 21 st century as shown in Figure 1. Specifically, compared to human resources developed by each university,

* Corresponding Author: Takashi Sasaoka, Email: sasaoka@ mine.kyushu-u.ac.jp, phone: +81 928023333

Copyright () 2018 Canamaple Academia Services, http://press.camdemia.ca

DOI: 10.15273/ijge.2018.03.028 
the project aims to develop more excellent human resources in terms of four following points: (1) to be internationally minded, (2) to be able to get an overview of the resource flow, and (3) to be capable of designing and managing. Moreover, in collaboration with the "KIZUNA (Bond) Program" promoted by JICA (4), it is also important to strengthen the bond between Japanese students in resources engineering and foreign exchange students from resourcerich countries. In accordance with these four items, we are planning to implement a collaborative education program based on the following four viewpoints: "international field surveys" to be more internationally minded, "graduate school exchange seminars" to be able to see things from broad perspectives, "resources management special seminars" to be more capable of designing and managing, and "international human resources exchange debates" to strengthen the ties between Japan and resource-rich countries.

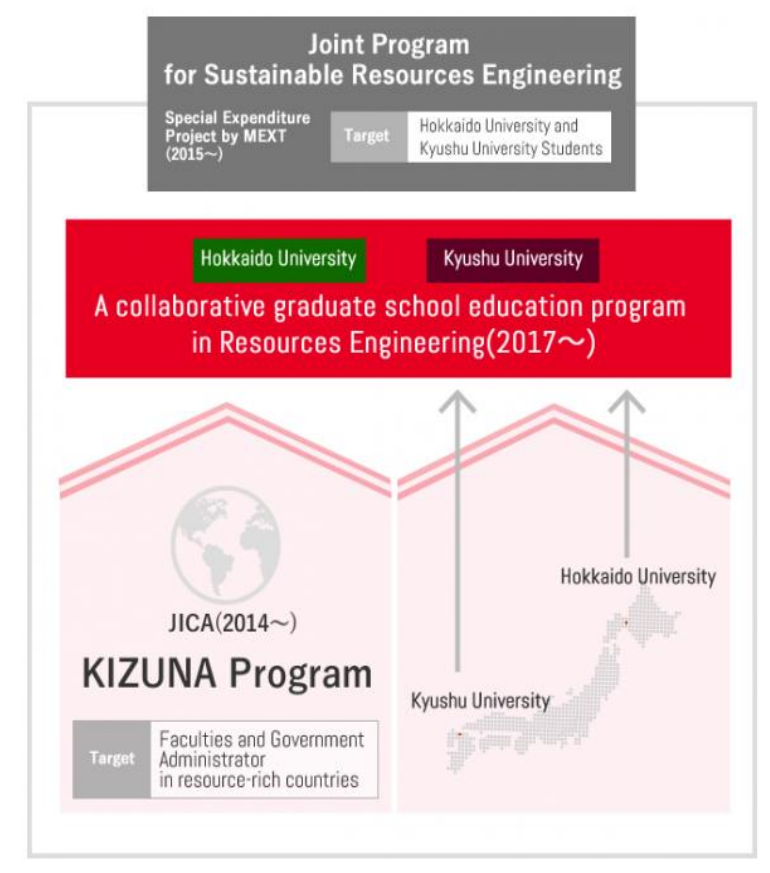

Figure 1 Scheme of joint program for sustainable resources engineering

\section{Significance and Effects}

\subsection{Social significance}

A big feature of this project is that foreign exchange students strategically invited from resource-rich countries and Japanese students are able to study together. In this sense, this education program will reinforce human networks between Japan and those countries and also contribute to securing resources for the future of Japan. On the other hand, in this project, foreign exchange students from those countries will study the methods of resource development using environmental preservation and recovery techniques that Japan has cultivated over many years; therefore, it is expected that this project will also contribute to the prevention of environmental destruction in those countries. It is, therefore, considered that this program has great social significance for both Japan and resource-rich countries.

\subsection{Effects of educational improvement}

Since Kyushu University and Hokkaido University have education programs with different features, through collaborating and sharing their education resources, it will be possible to develop a high level of human resources, which neither of them would be able to realize on their own. Moreover, regarding the development of resources management education, which is essential for Japan's resources education in the future, they will be able to realize top-notch education, although it is difficult for them to do alone, by sharing the connections with business people and overseas teaching staff that they have respectively.

\section{Curriculum}

\subsection{Human resource developed in the program}

Education policies of this program are as follows:

(1) Learning the wide-ranging knowledge of resource engineering;

(2) Abilities to design and manage resources development in consideration of international politics and economics;

(3) High international perspectives;

(4) Intercultural understanding.

\subsection{Curriculum for global leaders in resources fields}

This Curriculum aims to develop excellent human resources in terms of the three following points:

(1) To be internationally minded;

(2) To be able to get an overview of the resource flow;

(3) To be capable of designing and managing.

The following 4 unique seminars/practices are ready for this curse.

\subsubsection{Exchange seminar}

In order to acquire wide-ranging knowledge of resources engineering, exchange seminar is conducted. In this system, students belong to Kyushu University will stay Hokkaido University for one quarter to take classes held in Hokkaido University and vice versa. 8 subjects on upstream sectors of resources development are provided in Kyushu University. As the same, 8 subjects on downstream sectors of resources development are provided in Hokkaido University. Then, students should take more than 10 credits of specialized "Subjects A" provided in Hokkaido University during 1 quarter as shown in Figure 2.

\subsubsection{International field exercise}

In order to acquire an international perspective, field exercises will be held in a foreign country for 1 to 2 weeks. The training locations will be arranged by professors in Kyushu University and Hokkaido University. The field exercise in 2017 had been held in Czech Republic and 
Poland in the last year (Figure 3). The detail will be described later.

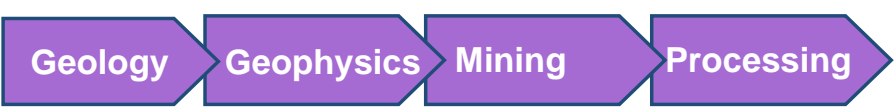

(a) Upstream sector (Mainly in KU)

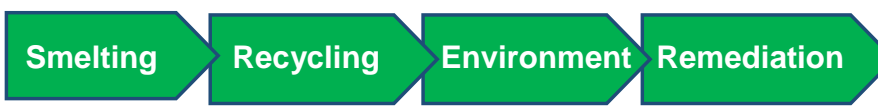

(b) Downstream sector (Mainly in $\mathrm{HU}$ )

Figure 2 Subjects of exchange seminar

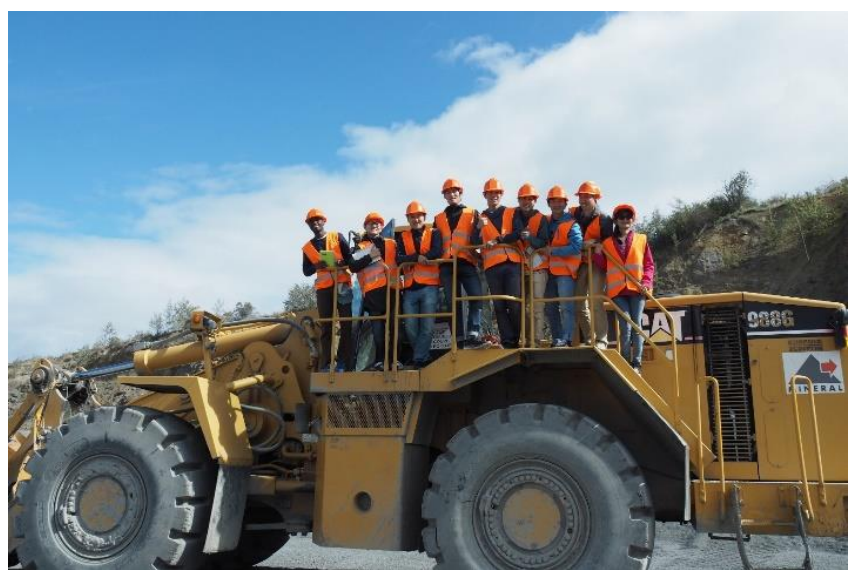

Figure 3 International field exercises

\subsubsection{Resources management I/II}

The education on resources management has not been sufficient in department of earth resources engineering. So, professors with broad experiences and various practical experiences will provide lectures to students in this program in order to acquire the abilities of design and management for resources development (Figure 4).

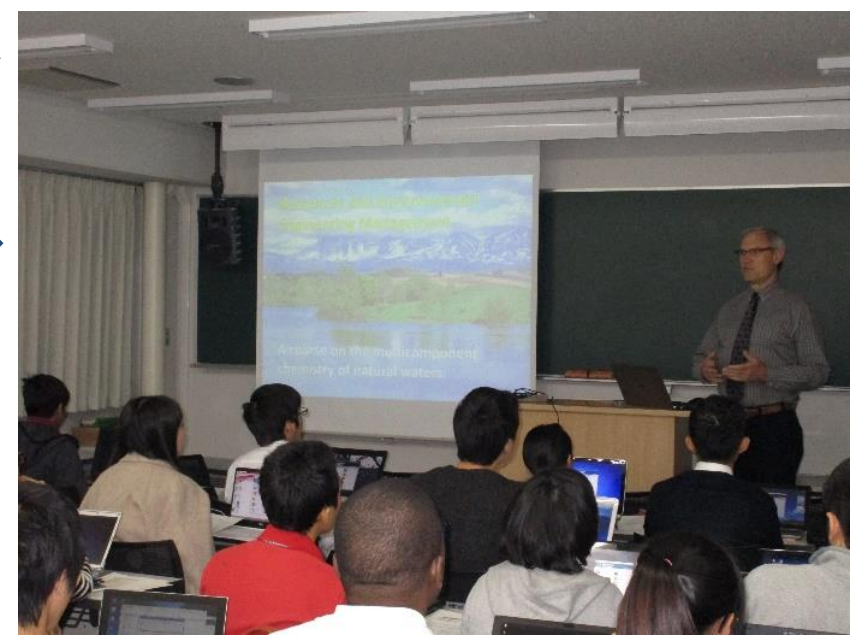

Figure 4 Class of resources management

\subsubsection{Human resources exchange seminar}

Human resources exchange seminar will be held in order to develop the ability of international negotiation and the international sensitivities.

\subsection{Lectures provided in this Curriculum}

In this Curriculum, students take the credits of Kyushu University and Hokkaido University. In Hokkaido University, 8 subjects on down stream sectors (Smelting, Recycling, Environment, and Remediation) of resources development are provided. In Kyushu University, 8 subjects on upstream sectors (Geology, Geophysics, Mining, and Processing) of recourses development are provided.

The lectures provided in this program and the schedules are shown in Figures 5 and 6, respectively.

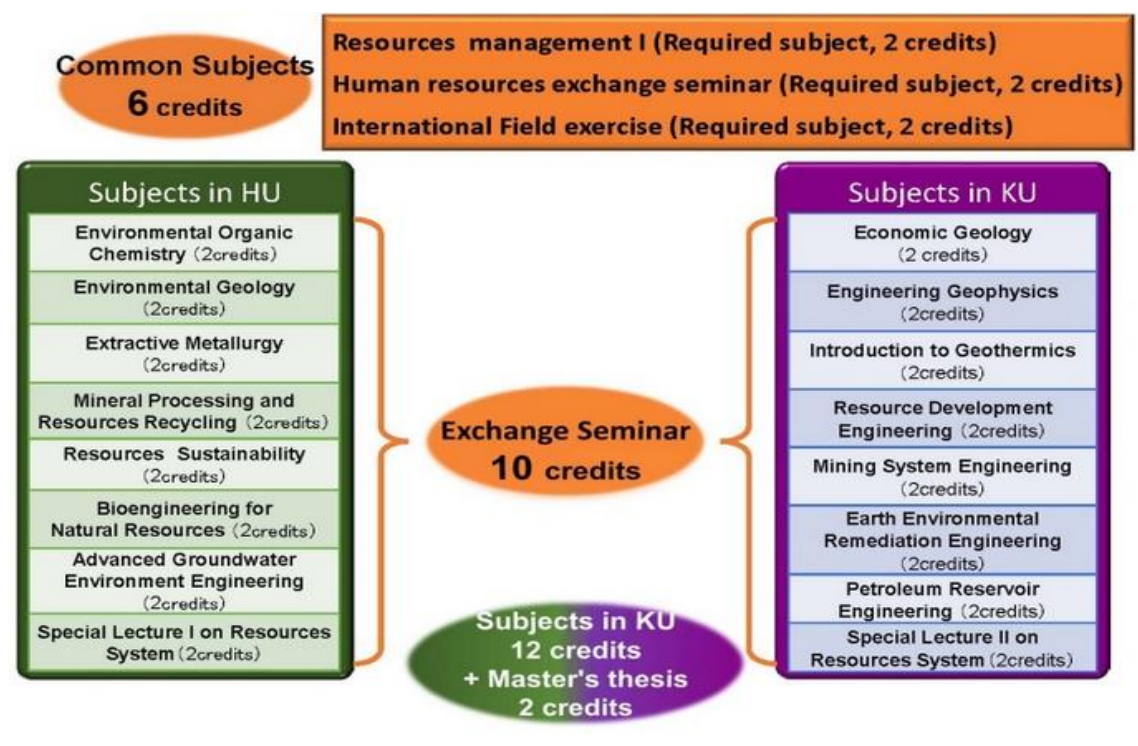

Figure 5 Lectures provided in this program 


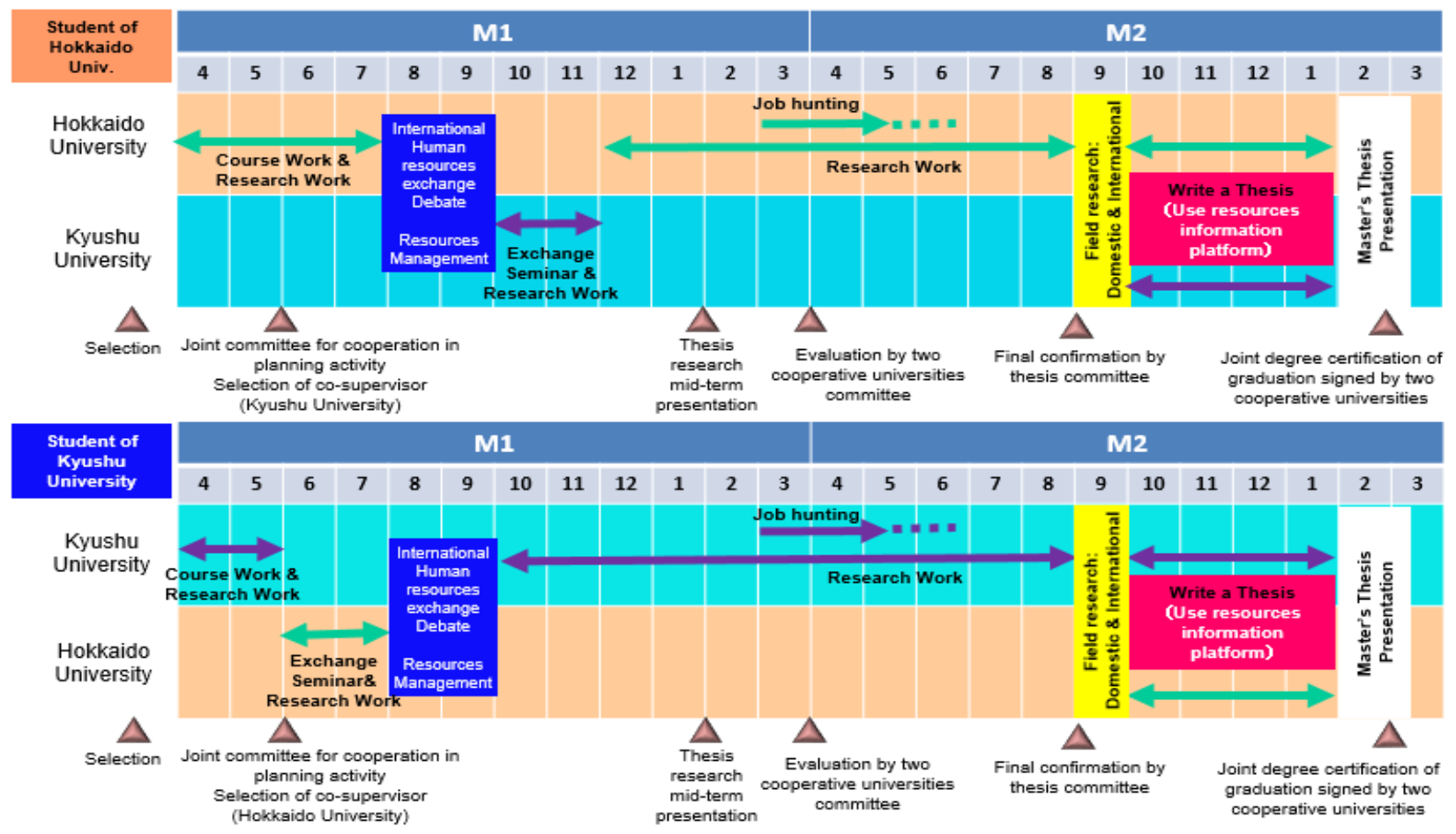

Figure 6 Joint degree's acquisition process

\section{International Field Exercise in 2017}

Kyushu University hold the International Field Exercise 2017 in Czech Republic supported by Technical University of Ostrava. We visited Open Pit Quarry, Underground Coal Mine, Slate Mine. Not only these places, we also visited the World Heritage like Wieliczka Salt Mine Museum.

Relationship between our department and the Faculty of Mining and Geology at Technical University of Ostrava has a long history with more than 30 years and we have signed an inter-university exchange agreement. Our colleges fully supported our International Field Exercise 2017. The reasons for the site selection are as follows:

(1) Relationship with counterpart;

(2) Long mining history (from development to closure) and ensure the mine sites to be visited;

(3) Cross-cultural understanding (difference between Europe and Asia, not only the way of thinking/concept but also geographic condition);

(4) Safety.

The number of participants is 16 including students and staffs. The schedule of International Field Exercise 2017 is listed in Table 1 . The overviews of each visiting site are described as follows.

\subsection{Open-pit quarry-Bohučovice}

The quarry produces aggregate for concrete, contents for asphalt and coat mixes, railway beddings, rocks for dam constructions, etc. The annual production in this mine is about 3 million tons. Students learned about the whole open pit mining operation, such as the mine planning and pit design, blasting operation, transportation, crushing, and environmental issues control. Moreover, they also had an opportunity to ride on a heavy equipment (Figure 7).

Table 1 Schedule of International Field Exercise 2017

\begin{tabular}{ll}
\hline \multicolumn{1}{c}{ Date } & \multicolumn{1}{c}{ Schedule } \\
\hline September $13^{\text {th }}($ Wed $)$ & Fukuoka->Prague \\
\hline September $14^{\text {th }}(\mathrm{Thu})$ & Prague->Olomouc \\
\hline September $15^{\text {th }}($ Fri $)$ & Open-pit quarry -Bohučovice \\
\hline September $16^{\text {th }}($ Sat $)$ & $\begin{array}{l}\text { Olomouc->Krakow } \\
\text { Auschwitz Birkenau German } \\
\text { Nazi Concentration and } \\
\text { Extermination Camp Museum }\end{array}$ \\
\hline September $17^{\text {th }}($ Sun $)$ & $\begin{array}{l}\text { Wieliczka Salt Mine Museum } \\
\text { (World Heritage) } \\
\text { Krakow -> Otrava }\end{array}$ \\
\hline September $18^{\text {th }}(\mathrm{Mon})$ & $\begin{array}{l}\text { VSB-TU Ostrava (Staff meeting } \\
\text { and lab tours }) \\
\text { Industrial museum- Dolní } \\
\text { Vítkovice }\end{array}$ \\
\hline September $19^{\text {th }}(\mathrm{Tue})$ & OKD underground coal mine \\
\hline September $20^{\text {th }}($ Wed $)$ & Slate mine-Radim \\
\hline September $21^{\text {st }}($ Thu $)$ & Ostrava -> Prague \\
\hline September $22^{\text {nd }}($ Fri) & Hieronymus mine \\
\hline September $23^{\text {rd }}($ Sat $)$ & Depart from Prague \\
\hline September $24^{\text {th }}($ Sun $)$ & Arrive at Fukuoka \\
\hline
\end{tabular}




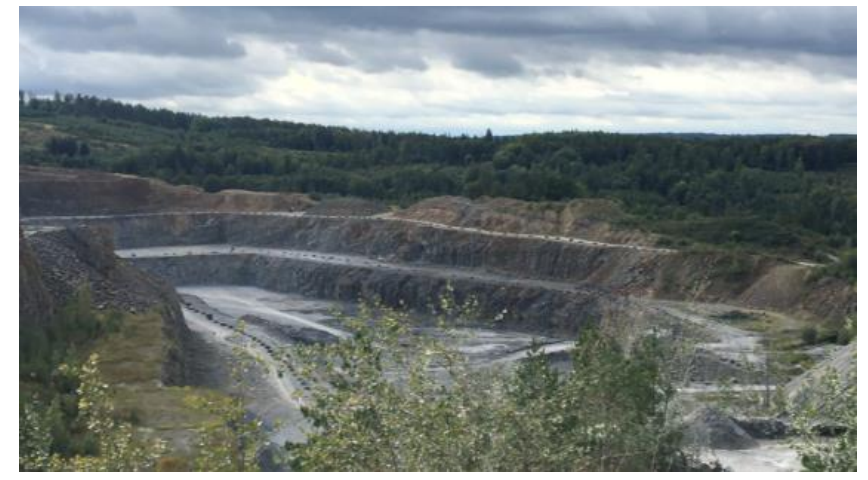

Figure 7 Open-pit slope in Bohučovice

\subsection{Wieliczka salt mine museum}

The Wieliczka salt mine located in the southern part of Poland close to Krakow city. This mine was commenced in 1044 to produce mainly a table salt. After almost 1,000 years' mining operation, the commercial production stopped in 1996 due to a high mining cost and severe mine water issues. The total amount of salt production is about 7.5 million tons. The total length of roadway is more than $300 \mathrm{~km}$ and the mining depth reached $327 \mathrm{~m}$ from the surface. During commercial operation, miners make the statues of mythology and goodness using salt rock and construct cathedrals in mined out area. This mine had been registered as UNESCO World Heritage Site in 1978. Through the visit of this mine museum, students could learn the history of underground mining systems, including mining methods, support systems, transportation systems, drainage systems, etc. Moreover, it was one of the examples to utilize a mined out area as a commercial space (Figure 8).

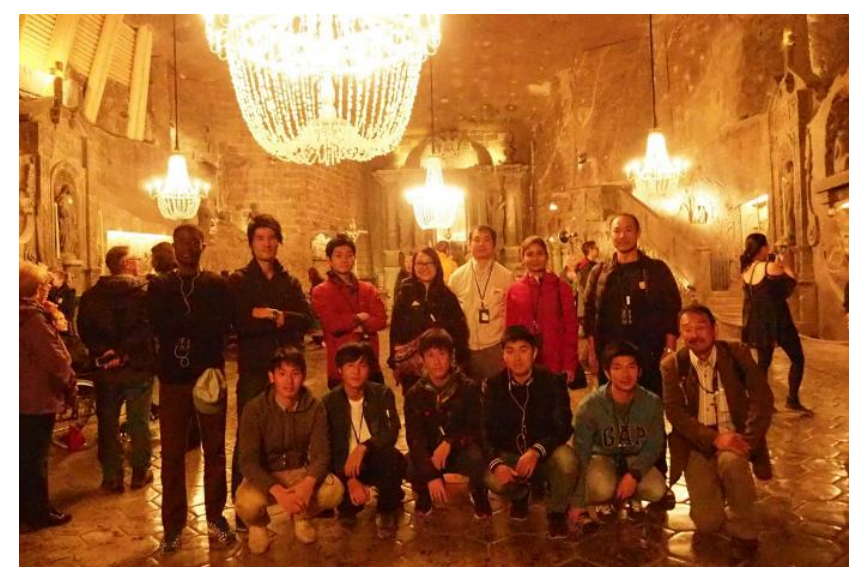

Figure $8 \mathrm{~A}$ cathedral constructed in mined out area

\subsection{Discussion of student exchange and laboratory tour in Technical University of Ostrava}

The Technical University of Ostrava was established in 1879. Now, there are 7 faculties and 11,000 students in total. They have many projects with EU countries. The faculties' meeting was held with our staffs, and the vice-dean and head of international affairs of Faculty of Mining and Geology, in order to discuss future collaboration, including student exchange and research. Students visited laboratories of Faculty of Mining and Geology in order to know the research topics and technologies to be developed. We also visited the University Geological Museum as shown in Figure 9.

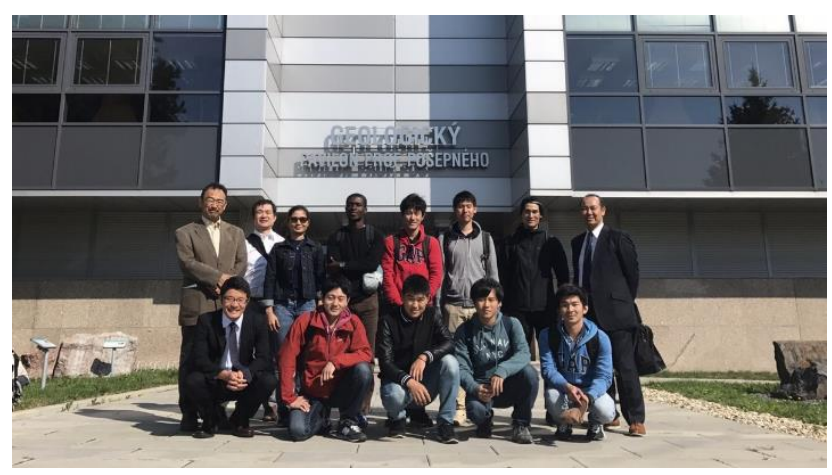

Figure 9 Geological museum in Technical University of Ostrava

\subsection{Industrial museum- Dolní Vítkovice}

The Dolni Vitkovice area became in 2002 a national cultural sight. Industrial compound with high furnaces had been used for 170 years to produce iron. We could learn about the production, function of individual construction to make crude iron from iron ore and coal (Figure 10).

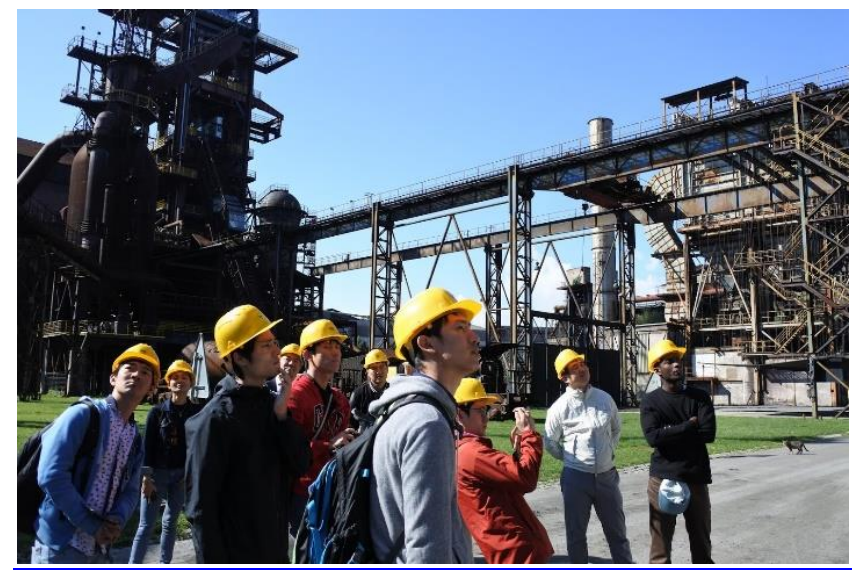

Figure 10 Blast furnace- Dolní Vítkovice

\subsection{OKD underground coal mine}

OKD is the only producer of hard coal (bituminous coal) in the Czech Republic. Its coal is mined in the southern part of the Upper-Silesian Coal Basin - in the Ostrava-Karviná coal district. OKD has three mines and the total annual coal production is about 9 million tons. All of them are deep mines (more than $1,000 \mathrm{~m}$ underground) and coal is mined using shafts and adit systems - nowadays exclusively by means of mechanized processes. The mining method is longwall advancing with controlled caving. The coal mining is carried out by means of shearers and plows. For supporting the roof in the faces individual self-advancing hydraulic shields are used. We learned about underground coal mining system, including development of headings, 
longwall face, transportation, ventilation, safety measures, etc. Advanced technologies introduced in this mine for safety and management were also learned (Figure 11).

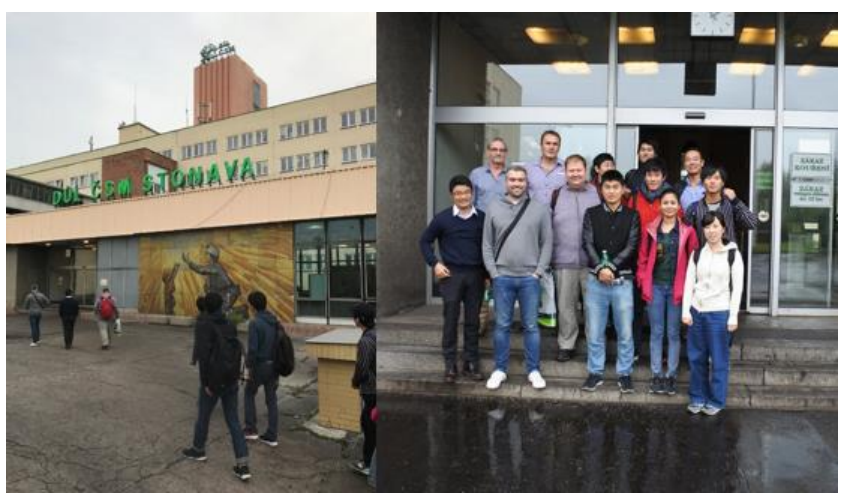

Figure 11 Main office of OKD Coal Mine

\subsection{Slate mine-Radim}

Originally, an extraction in the cadastral area of Svatoňovice started in 1930s. Now, a company Důl Radim a.s. prepares a new opening of the mine deposit in this territory by restoring the main crosscut. After the extraction is started, the raw material is used for the production of building stones, garden stones and crushed and milled slate products. In this mine, we could learn a compact underground mining system, small scale and sustainable operation. Moreover, it was a good opportunity to understand fundamental underground systems such as, extraction, support, transportation, ventilation, etc (Figure 12).

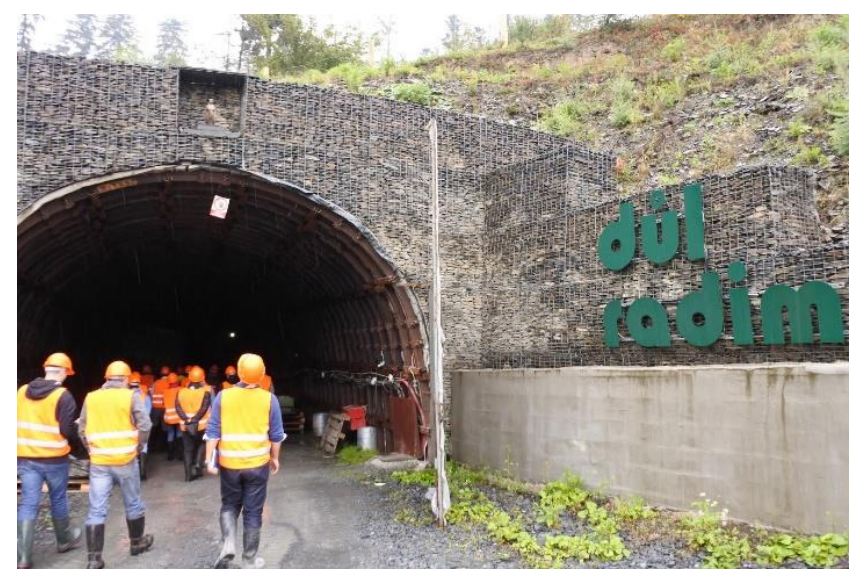

Figure 12 Portal of Slate mine-Radim

\subsection{Hieronymus mine}

The Hieronymus Mine, a cultural monument, is a unique witness of the mining culture and skills of our ancestors. The Hieronymus tin mine southwest of the former town of Čistá was registered by the mining authority in 1548 . During the course of its history, the Hieronymus Mine produced approximately 500-700 tons of tin. Although mine was never as rich and renowned as other workings in the area, it has survived in its original form. With numerous interruptions and varying yields, the mine operated until the end of World War I. Currently, the mine is undergoing an extensive and costly reconstruction as a museum for understand the history of mining technology (Figure 13).

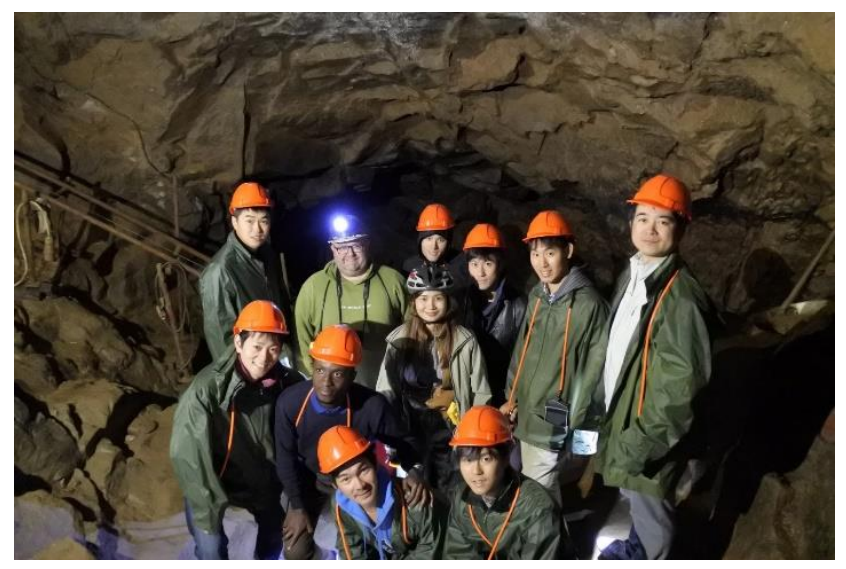

Figure 13 Hieronymus Mine

\subsection{Summary}

The International Field Exercises 2017 was a great opportunity to understand the mining systems in surface and underground mines. Moreover, the strategy of mine development and environmental protection, and the material flow in Europe could be learned.

\section{Development in the Future}

In Japan, there are only a few universities offering resources education. Among them Kyushu University and Hokkaido University have education programs with different features. They, however, have common performance of satisfactory international education and roles in "JICA KIZUNA Program" (mainly education for faculties in resource-rich countries). Therefore, there are few obstacles in collaboration between them, which enables them to promptly achieve the high-level resource education required from the society. In the future, they will experiment with the planned education program and verify its effects in order to launch a collaborative education program. Furthermore, this project aims to construct "a KIZUNA that will never be cut" with other resource-rich countries in the world by making the most of the connections formed while Japanese students and foreign exchange students from those countries study together.

\section{Acknowledgements}

The authors give grateful thanks to Dr. Pavel Stasa, Assistant Professor, Dr. Jiri Svub, Project Researcher, Technical University of Ostrava for their grate assistance and arrangement of International Field Exercises 2017 held in Czech Republic. 